\title{
Research on the MOOC and Multimedia Technology with Applications on Contemporary Literature Teaching in Colleges and Universities
}

\author{
Yan Li \\ Linyi University Feixian Campus, \\ Linyi,Shandong,273400 China
}

\begin{abstract}
In this paper, we conduct research on MOOC and multimedia technology with applications on the contemporary literature teaching in the colleges and universities. Modern and contemporary literature teaching should be recognized is aging, rigid, not adapt to the problems of the times, including floating style of general study, should be noticed and effectively solved. Now all kinds of conferences and activities a lot, all kinds of the quantitative indicators are "forced" people use more energy to fight for topic, research, teaching duty work could instead focus on less. Different school teachers on the same subject if able to communicate more, complement each other, each other will be beneficial to promote the reform of this course. This paper proposes the novel paradigm for the basic education patter for MOOC and multimedia based literature classes that are innovative.
\end{abstract}

Keywords-MOOC and Multimedia, Applications, Literature Teaching, Colleges and Universities.

\section{Introduction}

As the top form of culture, literature, in the form of highly personalized stay high level of the human spiritual pursuit, is the most close to the state of nature of human. Interpretation can freely on the level of life, in the face of literature and daily experience is too limited. Meaning of hermeneutics thinks that does not depend on interpretation and the interpretation of the object, but rather depends on both the interpretation and understanding in the process of the dialogue, in other words, the meaning itself should include interpreter, interpretation of the object, context and dialogue in four key elements, the interpretation of the object is not variable, the other three are in the change, therefore the humanities attributed in the rheological inevitably. Traditional literature teaching concept will be interpreters and interpretation of the object be treated as subject-object dichotomy, and illustrates the all objects were included in the present context, knowledge is unique and exclusive [1-2].

Choose the teaching method in teaching science, can achieve the ideal effect, to ensure the teaching achieve the teaching goal, scholars have put forward and discussed the selection of teaching methods. Any kind of teaching management system of formation is dominated by ideas, hold the management idea, can form the system of teaching management. Calls by the interests of managers and often has to obey the whole and that ignored by managers in the management of the initiative, enthusiasm and creativity, and in the process of academic freedom has not been able to get the attention they deserve. In short, the lack of humanistic care in the system design, respect personality, to promote the thorough understanding of managers and by managers and the best cooperation, can activate the potential of humanized management and realize the combination of institutionalized management and humanistic management. The author try to from two aspects of the generation and the basis of the basic course, explains a course that university teachers how to generate the optimization of the teaching methods. (1) Experienced a course of the discipline theory and knowledge that teaching method is the external manifestation of teacher intrinsic quality, the quality of the teachers' inner quality directly affects the optimization of teaching methods. (2) 
Change the teaching concept. To generate optimized teaching method is based on voluntary conscious conceptual change as the reasonable teaching plays a guiding role for teachers' teaching behavior, only change the reasonable teaching concept generate optimized teaching methods. (3) Widely absorbs the new achievements of theory and practice of education, the new experience, especially experience, development and innovation of existing advanced teaching methods, improve their own teaching behavior that initiative to generate your own teaching methods.

The one big characteristic of large-scale interactive MOOC based online education that it is also the one of the main attributes is different from the traditional teaching mode. In terms of the current, most of the traditional online teaching belongs to linear, completely belongs to unilaterally the compulsory indoctrination, interaction between teachers and students is not strong, that lead to students' learning efficiency is low, many problems cannot be timely and effective solution. But online education based on MOOC completely broke the situation, combined with a class implements the class of interactive teaching to improve the teaching quality and learning efficiency [3-4].

\section{Advantages of Teaching Literature \\ - Literature can be very enjoyable to read. \\ - - It provides examples of different styles of writing, mirrors various authentic uses of the language. \\ - - It is a good basis for vocabulary expansion. \\ - It fosters reading skills. \\ - - It can supply an excellent jump-off point for discussion or writing. \\ - - It involves emotions as well as intellect, which adds to motivation and may contribute to personal development. \\ - - It is part of the target language culture and has value as part of students' general education.}

Figure 1. The Meaning of the Modern College Literature Education

In this paper, we conduct research on the MOOC and multimedia technology with applications on the contemporary literature teaching in colleges and universities. Fashionable whole world MOOC is not an accident, its education concept put forward not only promotes the innovation of the education technology, but also promoted the people on the education idea, education system, curriculum design and development, teaching organization, credit certification, the reflection and reform of the teaching staff construction. In the later parts, we will discuss the issues in detail.

\section{The Proposed Methodology}

The Concepts of the College Education. Colleges and universities also pay more and more attention to the knowledge management, knowledge management has injected new vitality for the management reform of colleges and universities. In the process of deepening the reform of education teaching in colleges and universities how to maximize the development, grasp and use of knowledge resources, improve the quality of talent training, school education teaching reform and development of strategic issues. Since the system reform of the colleges and universities, because of the teachers' evaluation disdainful of teachers' scientific research achievements, combined with the construction of teaching evaluation management system and unscientific, cause the teachers' scientific research light teaching "phenomenon has become increasingly serious, the teaching reform. Therefore, we should pay special attention to various teaching behavior of university teachers, the teaching method is a microcosm of the various kinds of teaching behavior.

To strengthen the construction of teaching team is an important part of teachers' team construction, and also is an important part of school discipline construction that is the key to promote sustainable development of the school that holds the listed advantages. (1) Any teaching system, even a course, also can become very complex, which requires teachers of colleges and universities should update their concepts of education, to establish the idea of professional 
development, and actively explore new education teaching method, make oneself in the professional field of consciousness, professional knowledge with professional skills development. (2) Way based on team work, and emphasizes the team cooperation and collaboration in the work. From the perspective of efficiency, the team can through internal communication, integration, among its members can be complementary skills and experience, the combination of a wide range of the skills and knowledge, enables the team to meet various challenges. (3) Establish excellent teaching team, through mutual inspiration, supplement and motivation between teachers, that will not only can lead to higher individual work efficiency, but also conducive to promote the more positive relationships between team members. From the point of the teaching process, its characteristic is to teach knowledge and exploration process. In the operation of the teaching in colleges and universities knowledge is not only a kind of material, but also a process. College teachers should not only teach students knowledge of a particular field, but also to teach the students to explore the method of knowledge [5-6].

The Multimedia Technology. From the perspective of language interpretation, of the definition of the multimedia is a saying: "multimedia is the combination of two or more media: text, graphics, animation, video, static and dynamic video, voice." Multimedia rich forms and huge capacity for the transmitting information gives modern teaching pattern with a new face. There are three kinds of the common multimedia teaching mode.
- Studio classroom multimedia teaching mode. Accept from a computer or basic video projector booth image signal, its projection on the electric curtain, for all students to watch, sound signal through audio equipment and sound in the teaching implementation synchronization.

- The network multimedia teaching mode. Relative to pure multimedia classroom, network multimedia classroom construction costs, at present, many colleges and universities also have the construction of network multimedia classroom, that just penetration rate is not high.

- Distance educational multimedia teaching mode. This teaching mode is to the general network courseware of courses, teaching outline, schedule guidance, important or difficult analysis, homework and other stored in server, different time and place students according to their own needs, through the browser software to access the remote server, choose the content of need.

According to the different content choose different teaching forms, need more graph, table, or the animation to explain the process of problem, presentation, we need to use multimedia technology to assist teaching to enhance the classroom teaching intuitive, vivid, more conducive to the students to understand. Accordingly, in the figure two, we demonstrate the principles. 


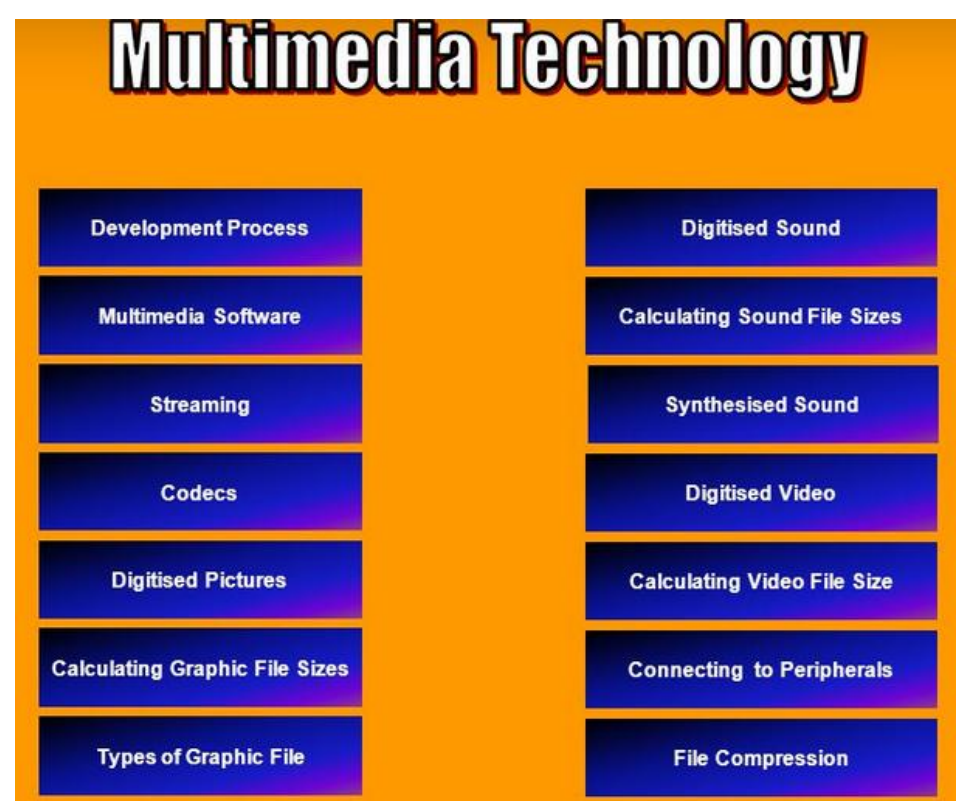

Figure 2. The Characteristics of the Multimedia Technology

The MOOC. MOOC in China's development must be based on the characteristics of the education reform in our country. The MOOC has many advantages, but according to the actual situation of the China's higher education, MOOC video teaching and the teaching model of integration of classroom teaching is the development direction of Chinese higher education in the future, this mixed mode into video courses will be teaching and classroom discussion two levels of teaching, can make full use of information technology is convenient, and can make up for the shortage of the traditional classroom teaching, motivate students' autonomous learning and improve the innovative ability of students [7].

MOOC virtual experiment technology and is the core of the open experiment teaching, it is also one of MOOC practitioners are very concerned about the topic. At present, with the development of the computer technology and network of large-scale popularization, many colleges and universities at home and abroad are in manpower, material resources and financial resources construction of virtual laboratory as make full use of computer simulation, performance of the simulation and calculation, not only traditional laboratory work and realize the traditional laboratory can't do things.

In remote education into comprehensive connotation MOOC should notice for the understanding of learning objects into the local comprehensive that is set up according to the learner learning ability and situation targeted set of teaching content. Accurately grasp the learner's knowledge level, ability to learn, learning experience and professional background, flexible adjustments to the comprehensive teaching content. In the professional qualification certification, MOOC remote education professional skill appraisal institutions should be according to the requirements of the MOOC remote education schools and educational philosophy to develop the professional training goal and scientific evaluation criteria system, through continuous assessment of learners in many other aspects of the knowledge, ability and quality should reach level, on the learner's comprehensive professional quality appraisal. 


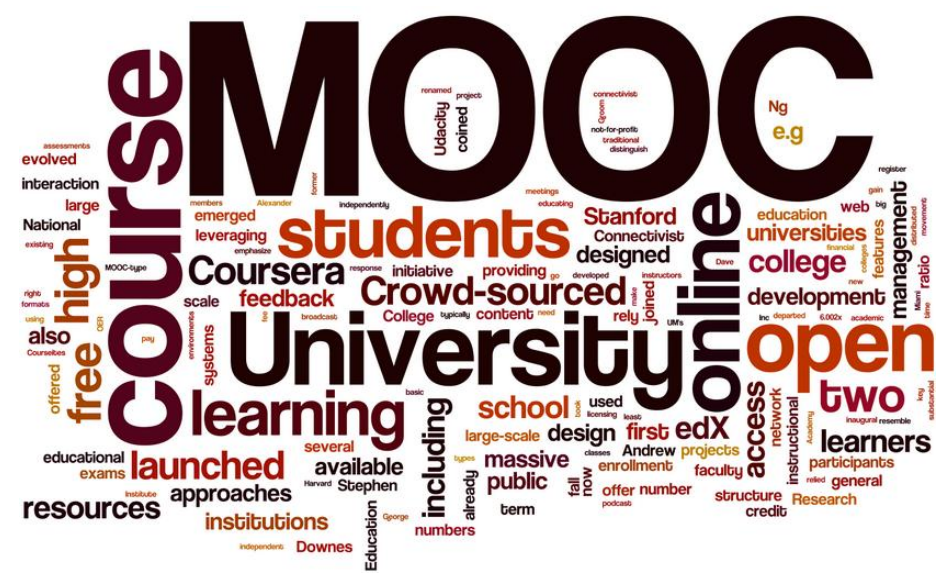

Figure 3. The Keywords of the MOOC Concepts and Principles

The Contemporary Literature Teaching. Literature teaching and language teaching is divided into two related academic field, not only far-fetched and inappropriate. Because literature is composed of language, and language level can be read by literature and ascend. Therefore, literature teaching is closely connected with language teaching. In fact, the literature in the entire plays many important roles in the process of teaching and learning. Folk literature teaching nature can also create some new forms, such as the non-material cultural heritage inheritance person please go to the classroom, on the application of multimedia teaching methods to teaching, and so on. Can't go too far, however, that we forget why we set out, not the subject for the research of personalized the basic characteristic of the abandoned. Therefore, how to make the root of the folk literature in teaching, the technicality and literariness is based on the classroom, it is very necessary [8].

We are in the process of Chinese ancient literature teaching in addition to the traditional teaching method, also adopted such as the heuristic method of teaching, situational teaching method, speech debate, to participate in performances, research-oriented teaching method and classification teaching method and so on the many kinds of teaching method, and through repeated practice, has paid off. (1) Diversified teaching methods. With the progress of science and technology and the diversification of teaching materials and other auxiliary materials, traditional literature teaching has not been able again to scripted way, must use all kinds of teaching materials and auxiliary data, such as images, audio, animation and other multimedia information. With the progress of the science and technology, the network and computer also become indispensable means literature teaching. (2) Literature is often taken for affair, has nothing to do with the reality, but if can be used in foreign language teaching, literature teaching and language teaching, the foreign language teaching can greatly increase breadth and depth. (3) In the process of language teaching, the students can be classified into groups. Group activities can indeed provide that won't let student too tense atmosphere, and members of the group psychological support, in the case of a face-to-face discussion, students produce language output.

\section{Conclusion}

In this paper, we conduct research on the MOOC and multimedia technology with applications on the contemporary literature teaching in the colleges and universities as teaching method is the external manifestation of teacher intrinsic quality, the quality of the teachers' inner quality directly affects the optimization of teaching methods. Teachers in colleges and universities is different from the primary and secondary school 
teachers, in view of the changes of curriculum content, not only to have the course system of subject knowledge, a solid theoretical foundation, but also to the course's subject in the field of research status and the frontier problem have a more comprehensive understanding, can be appropriately to use teaching methods to show the rich course content. Under this background, we propose the novel perspective of making the MOOC and multimedia technology with applications on the contemporary literature teaching in the colleges and universities to serve as the new perspective.

\section{Reference}

[1] Goodwyn, Andrew. "The Status of Literature: English teaching and the condition of literature teaching in schools." English in Education 46.3 (2012): 212-227.

[2] Farrington, Camille A., et al. Teaching Adolescents to Become Learners: The Role of Noncognitive Factors in Shaping School Performance--A Critical Literature Review. Consortium on Chicago School Research. 1313 East 60th Street, Chicago, IL 60637, 2012.

[3] Al-Mahrooqi, Rahma. "An Investigation of Literature Teaching Methodologies at a
Higher Educational Institution in Oman." TESOL Journal 6 (2012): 172-180.

[4] Benton, Stephen L., and William E. Cashin. "IDEA PAPER\# 50 Student Ratings of Teaching: A Summary of Research and Literature." (2012).

[5] Hoidn, Sabine, and Kiira Kärkkäinen. Promoting skills for innovation in higher education: A literature review on the effectiveness of problem-based learning and of teaching behaviours. No. 100. OECD Publishing, 2014.

[6] Junyue, Li Xuemei Chang. "The Cognitive Turn of English and American Literature Teaching under the Frame of CBI [J]." Journal of Guangdong University of Foreign Studies 1 (2012): 025.

[7] Teo, Timothy, and Verica Milutinovic. "Modelling the intention to use technology for teaching mathematics among pre-service teachers in Serbia." Australasian Journal of Educational Technology $31.4 \quad$ (2015): 363-380.

[8] Garza, Susana, Liliana Portilla, and Keri Shannon. "Perspectives of teaching Mexican American students as reflected in multicultural literature." Journal of Border Educational Research 9.1 (2013). 